\title{
Ruptured ovarian artery aneurysm in puerperium: a rare occurrence
}

\author{
Bindu Bajaj ${ }^{1}$, Sunil Kumar Bajaj ${ }^{2}$, Ritu Misra ${ }^{2}$, Rohini Gupta ${ }^{2}$
}

\author{
${ }^{1}$ Department of Obstetrics \& Gynaecology, V M Medical College \& Safdarjung Hospital, New Delhi, India \\ ${ }^{2}$ Department of Radiodiagnosis, V M Medical College \& Safdarjung Hospital, New Delhi, India
}

Received: 07 December 2014

Accepted: 23 December 2014

\section{*Correspondence:}

Dr. Sunil Kumar Bajaj,

E-mail: drskbajaj@rediffmail.com

Copyright: (C) the author(s), publisher and licensee Medip Academy. This is an open-access article distributed under the terms of the Creative Commons Attribution Non-Commercial License, which permits unrestricted non-commercial use, distribution, and reproduction in any medium, provided the original work is properly cited.

\begin{abstract}
We present a rare case of Ovarian Artery Aneurysm in a puerperium. It was managed by endocopic banding of the ovarian artery following failed attempts at endovascular embolisation. The patient remained stable on three months follow up. The pathogenesis of this rare condition is also discussed.
\end{abstract}

Keywords: Puerperium, Aneurysm, Ovarian artery

\section{INTRODUCTION}

Ruptured Ovarian artery aneurysms are usually associated with pregnancy and puerperium. This is believed to be due to hormonal and haemodynamic changes occurring during this period that predispose to aneurismal dilatation of vessel and rupture. A significant fluid shift during this period and raised cardiac output lead to rupture of aneurysm.

Fewer than 20 cases in the world literature have been recorded till date. It is important to be aware of this entity in order to avoid misdiagnosis and delay in management.

\section{CASE REPORT}

A P7 L3 35 year old woman married for 17 years had delivered a baby vaginally one month prior to admission. She complained of severe pain lower abdomen 2 days following partum and reported to nearby medical college, where she was diagnosed to have a large left psoas abscess. She was operated 2 days later and found to have a large retroperitoneal haematoma, $180 \mathrm{cc}$ of haematoma collection was aspirated by retroperitoneal approach. She continued to have recurrent pain lower abdomen. A contrast enhanced CT done on day 8 showed a large haematoma in left pararenal and paracolic gutter in RP region with a ruptured aneurysm. CT angiogram done confirmed presence of large haematoma surrounding left ovarian artery aneurysm $(1.5 \mathrm{~cm})$ with no active leak. Patient's haemoglobin was only $4.2 \mathrm{gm} \%$ but haemdynamically maintained with BP $140 / 90 \mathrm{mmHg}$. Patient was referred to us on day 12.Patient had tender abdomen with guarding. The gynae examination was unremarkable. After giving two units of blood she was taken up for embolization of left ovarian artery.

Left ovarian artery was accessed by right trans-femoral route. Repeated attempts were made to catheterize left ovarian artery selectively using 'mother and child technique' with different catheters failed over next 2 hours. These resulted in ostial damage and artery was thought to be totally occluded at its origin albeit by default.

A repeat CT angiogram done 10 days later showed that the endovascular intervention had failed and the aneurysm stayed put surrounded by massive haematoma in retroperitoneal region (Figure 1-3). Successful Endoscopic banding of the left ovarian artery at its origin was done two weeks later. Check CT angiogram done subsequently confirmed the success of surgical procedure. 
The patient has remained haemodynamically stable throughout.

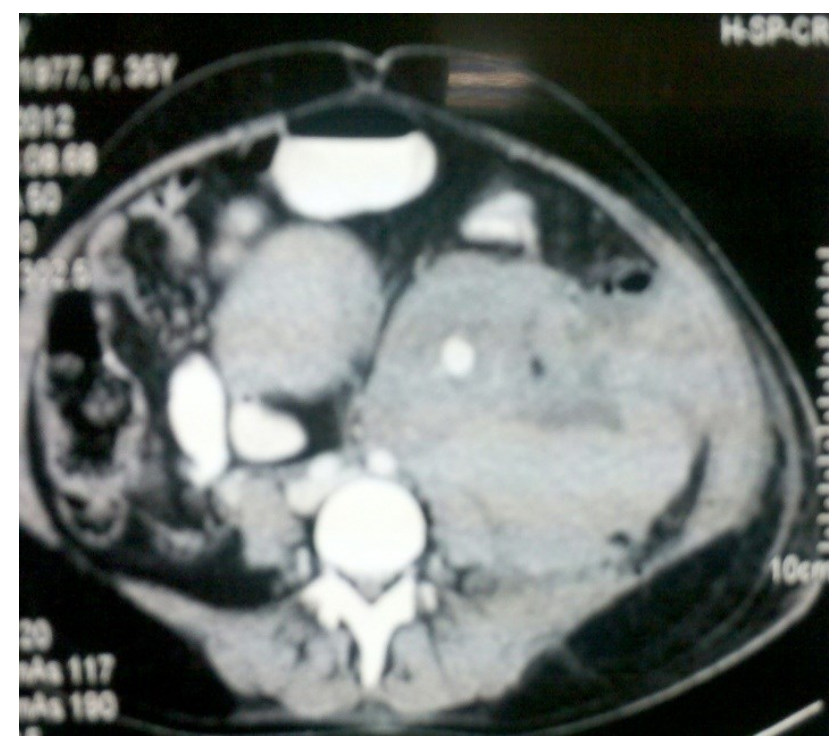

Figure 1: Axial CECT image showing a large left pelvic collection surrounding an aneurysm.

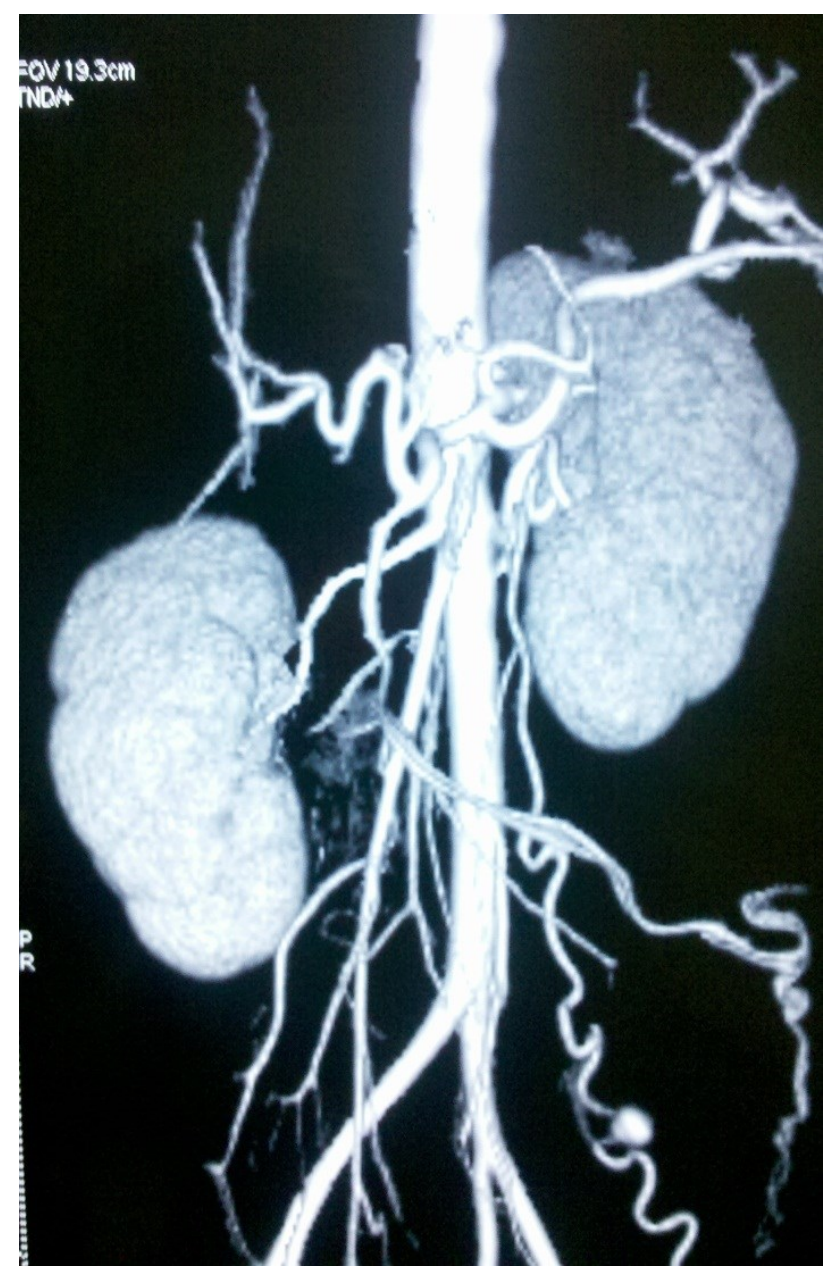

Figure 2: Volume rendered coronal CT angiography image showing left ovarian artery aneurysm.

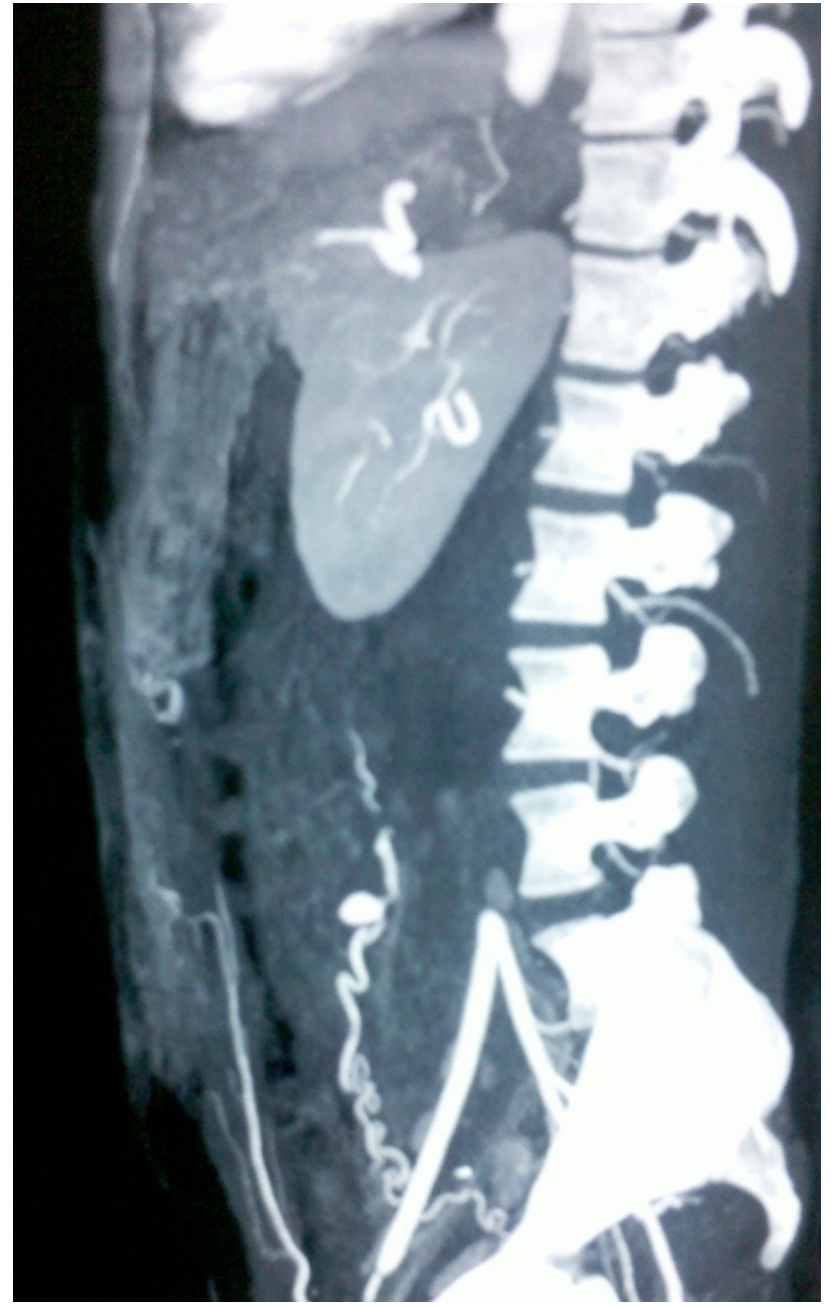

Figure 3: MIP saggital CT angiography image showing left ovarian artery aneurysm.

\section{DISCUSSION}

Pregnancy and puerperium are a physiological state of woman wherein significant and marked shifts of circulatory haemodynamics and endocrinal changes occur, which to date are still incompletely understood.

Majority of ruptured arterial aneurysm in women of reproductive age group are pregnancy related. The significant hemodynamic shifts and hormonal variations of pregnancy appear to predispose to arterial alterations such as intimal and media hyperplasia, fragmentation of reticular fibres and loss of corrugation of elastic fibres, which may all lead to new aneurysm formation and/or weakening of preexisting aneurysms ending in their rupture with catastrophic effects. ${ }^{1}$

Up to $10 \%$ of maternal deaths occur due to cerebral hemorrhage, many caused by ruptured aneurysm. A ruptured intracranial aneurysm complicates 1 in 10000 to 1 in 2000 pregnancies. Up to $1 / 5$ of all aneurysms will rupture in pregnancy or early puerperium most of the times in first pregnancy. ${ }^{2}$ The pregnancy is associated 
with five times increased risk of aneurismal rupture than that of age matched non pregnant women. ${ }^{3}$

The puerperium is period where there is significant increase in risk of rupture. It has been documented that aneurismal rupture rarely occurs during labour and delivery despite evidence of marked haemodynamic shifts occurring during this period. ${ }^{3}$

In the first 2-3 days postpartum there is $15-30 \%$ increase in circulating blood volume due to elimination of placental circulation and shift of Fluid from interstitial compartment to intravascular compartment

There is dramatic increase in cardiac output to the tune of $75 \%$ immediately post-partum, which decreases $28 \%$ in first fortnight following partum. Hence the vessel walls are subjected to significantly increased stress caused by marked increase in Cardiac output during the first two weeks following delivery. ${ }^{3}$

Non intracranial vascular aneurysms associated with pregnancy and puerperium occur in order of frequency in splenic, aortic renal, coronary and ovarian arteries. To date only 14 cases of ovarian artery aneurysm rupture have been reported in English medical literature apart from around half a dozen cases in non-English literature.

It has been observed that aneurysm rupture occurs in either $3^{\text {rd }}$ trimester or in puerperium. These rupture do not occur during labour (Reasons unexplained although logically they should be more common in labour due to sharp and extreme haemodynamic changes). This can be sought to be explained by hormonal changes during labour which enable spring like stretchibility of muscle fibres including smooth muscle fibres of vessels protecting aneurysm from rupture despite severe haemodynamic changes.

Review of 14 cases of ovarian artery reported in English medical literature shows that nearly all of them were in puerperium, with one case probably rupturing in second stage of labour. ${ }^{4-6}$

Four of the cases of ovarian artery rupture were unrelated to pregnancy. In many instances, the rupture of an ovarian arterial aneurysm may resemble other less serious diseases (as in present case which was thought to be psoas abscess), thereby delayieding the correct diagnosis and management until a catastrophe strikes.

Endovascular embolization has been done successfully in four cases of ovarian artery aneurysm. ${ }^{7-10}$

Surgery however remains the mainstay of these cases, particularly where endovascular management is technically unsuccessful or where such facility is unavailable.

Funding: No funding sources

Conflict of interest: None declared

Ethical approval: Not required

\section{REFERENCES}

1. Barrett JM, Van Hooydonk JE, Boehm FH. Pregnancy-related rupture of arterial aneurysms. Obstet Gynaecol Surv. 1982;37(9):557-66.

2. Wiebers DO. Subarachnoid hemorrhage in pregnancy. Semin Neurol. 1988;8:226-9.

3. Samuel C. Hughes, Gershon Levinson, Mark A. Rosen. The puerperium. In: Samuel C. Hughes, Gershon Levinson, Mark A. Rosen, eds. Shnider and Levinson's Anaesthesia for Obstetrics. 4th ed. Philadelphia: Lippincott Williams and Wilkins; 2001: 238.

4. Høgdall CK, Pedersen SJ, Ovlisen BO, Helgestrand UJ. Spontaneous rupture of an ovarianartery aneurysm in the third trimester of pregnancy. Acta Obstet Gynaecol Scand. 1989;68(7):651-2.

5. Kodaira Y, Iwamura $\mathrm{T}$, Hoshino $\mathrm{H}$, Takahashi $\mathrm{K}$, Kawahigashi Y, Matsumoto K. Spontaneous rupture of aneurysms of the ovarian artery at times remote from pregnancy. J Nippon Med Sch. 2014;81(2):1015.

6. Weedin EA, Mercer LT, Wood DL, Baker E. Ovarian artery aneurysm after postpartum hemorrhage: a case report. Obstet Gynaecol. 2014;123(Suppl 1):177S.

7. Burnett RA, Carfrae DC. Spontaneous rupture of ovarian artery aneurysm in the puerperium. Two case reports and a review of the literature. Br J Obstet Gynaecol. 1976;83(9):744-50.

8. Poilblanc $\mathrm{M}$, Winer $\mathrm{N}$, Bouvier A, Gillard $\mathrm{P}$, Boussion F, Aubé C, et al. Rupture of an aneurysm of the ovarian artery following delivery and endovascular treatment. Am J Obstet Gynaecol. 2008;199(4):e7-8.

9. Slaba S, Kazzi H, Abd O, Nassar J, Nasnas R. Glue embolization of an unruptured ovarian aneurysm. J Mal Vasc. 2010;35(4):266-9.

10. Rathod KR, Deshmukh HL, Asrani A, Salvi VS, Prabhu S. Successful embolization of an ovarian artery pseudoaneurysm complicating obstetric hysterectomy. Cardiovasc Intervent Radiol. 2005;28(1):113-6.

DOI: $10.5455 / 2320-1770$. ijrcog20150254

Cite this article as: Bajaj B, Bajaj SK, Misra R, Gupta

$\mathrm{R}$. Ruptured ovarian artery aneurysm in puerperium: a rare occurrence. Int J Reprod Contracept Obstet Gynecol 2015;4:272-4. 